\title{
Customer-oriented risk assessment in Network Utilities
}

\author{
${ }^{1}$ Juan F. Gómez Fernández \\ ${ }^{1}$ Adolfo Crespo Márquez* \\ ${ }^{2}$ Mónica A. López-Campos
${ }^{1}$ Department of Industrial Management I, School of Engineering, University of Seville, Camino de los Descubrimientos $s / n, 41092$, Seville, Spain
${ }^{2}$ Department of Industrial Engineering, Universidad Técnica Federico Santa María, Av. España 1680, Valparaíso, \\ Chile
}

* Corresponding author. Tel.: +34 954487215

E-mail addresses: juan.gomez@iies.es (Gómez Fernández), monica.lopezc@usm.cl (López-Campos), adolfo@esi.us.es (Crespo Márquez)

\begin{abstract}
For companies that distribute services such as telecommunications, water, energy, gas, etc., quality perceived by the customers has a strong impact on the fulfillment of financial goals, positively increasing the demand and negatively increasing the risk of customer churn (loss of customers). Failures by these companies may cause customer affection in a massive way, augmenting the intention to leave the company. Therefore, maintenance performance and specifically service reliability has a strong influence on financial goals. This paper proposes a methodology to evaluate the contribution of the maintenance department in economic terms, based on service unreliability by network failures. The developed methodology aims to provide an analysis of failures to facilitate decision making about maintenance (preventive/predictive and corrective) costs versus negative impacts in end-customer invoicing based on the probability of losing customers. Survival analysis of recurrent failures with the General Renewal Process distribution is used for this novel purpose with the intention to be applied as a standard procedure to calculate the expected maintenance financial impact, for a given period of time. Two case studies in a telecommunications services company are presented in order to illustrate the applicability of the methodology.
\end{abstract}

Keywords: Network Utilities, Customer affection, Reliability Analysis, Generalized Renewal Process

\section{INTRODUCTION}

Within the Services Sector, Network Utilities provide services to clients distributed in an infrastructure network (gas, water, electricity, telecommunications, etc.). Their infrastructures are usually organized and composed by a high number of dispersed elements, supported in hierarchical structures and replicated by distribution areas. These companies are capital intensive [5], meaning decades for pay-back on investments. Additionally, they have an intense and long lasting relationship with customers and consequently, quality perceived and demanded by them has a strong impact on the fulfillment of financial goals, positively increasing demand and negatively increasing risk of customer churn. Accordingly, in a competitive market, these companies are always trying to increase their market share and "customer life-cycle value." The main strategies by which this is done are: retaining actual customers; building customer loyalty and; capturing new potential customers in geographical territories. Therefore, customer opinion is essential and extremely decisive for the consideration of future investments [7].

Customer requirements, attitudes and behavior are not always the same, even among similar groups or at different times. There are several methods for quality measurement according to the attributes of a service, considering their importance or their contribution for the company to provide value [11]. However, a global measurement of the quality perceived by customers is not an easy task, because of the influence of subjectivity in their opinions ("...every customer perceives service quality differently", [23]). This is why many authors concentrate their efforts in evaluating significant interactions (called critical incidents) [12, 13]. Quality measurement in a service must evaluate feasible customer requirements about it, such as those related to the ability to respond to contingencies, the reliability and the security of the service [10]. Subsequently, service quality must be analyzed considering the positive and negative feelings of customers 
concerning service issues and the supplying company. For this, it is necessary to correctly define customer segmentation, in order to discover the needs of actual or potential customers [8].

Moreover, in a very competitive environment a fast response to problems may generate customer retention and loyalty [16 \& 17]; better availability and cost reduction may allow a decrease in the price of the services; and the sum of these parts is internal motivation, image and external business reputation [18]. Thus, more reliable services are appreciated in the sector of network utilities where contracts and standards revolve around of service level agreements (SLAs). Service quality will be accepted by the customers within a tolerance level, but ¿how do we know what this level is? We know that it will be modified depending on failure occurrence and recurrence. For that reason, maintenance departments should be considered crucial for network utilities [4], pursuing to keep the service delivery reliable, with maximum quality and performance. Focusing on the customer oriented service quality, a maintenance department contributes $[1,2,3]$ strongly to:

- Satisfy customer needs and loyalty, fulfilling the service reliability;

- Enhance the business image along with the ability to capture new customers;

- Reduce service costs and avoid unexpected failure costs;

- Improve productivity, increase availability.

Questions at this point arise: How can we measure service quality and the impact that maintenance has on it? How can we estimate maintenance quality (and mainly non-quality) costs? In special cases, as for important clients, or when we may suffer risk of financial loss, it could be useful to launch alerts and alarms about these issues when failures appear due to maintenance performance. Strategic, tactical and operative decisions will in turn become easier to handle. The difficulty of measuring the impact of maintenance activities on the quality of service and estimation of non-quality costs complicates decision-making in maintenance departments. [6]. By proceeding in that way, we arrive to a point where we can see the tradeoffs between gaining in service performance versus increasing maintenance costs [30,31]. Well-managed proactive maintenance, through proper prevention and inspection, will avoid internal [9] and external nonquality costs in network utilities.

In this way, perceived and demanded quality could be measured through maintenance performance in critical incidents, positive or negative, in the relationship with the customers concerning the number and type of customer complaints because of service failures. To illustrate this, the research presented in this paper aims to provide basic guidance for maintenance decision-making processes, in evaluating the impact of network reliability on customer satisfaction and on customer retention and loyalty. We develop a methodology that technically and financially describes how the recurrence of failures is correlated with customer abandonment. This analysis allows the evaluation of the use of financial resources for maintenance activities and the financial consequences of reliability incidents. With this purpose, our article is organized as follows: Section 2 reviews maintenance impact on quality in terms of costs in order to orientate the value of maintenance performance on financial goals. In Section 3 we develop a methodology to evaluate the impact of network unreliability on customer loyalty when companies deliver services, applying the Generalized Renewal Process (GRP) model from statistical data analysis to predict customer behaviors towards service abandonment (especially when considering recurrent failures). Within Section 4, we present a case study from a telecom company that analyzes data sets containing information about the loss of customers and the failure recurrence for a certain period of time. We finish with conclusions and future research challenges.

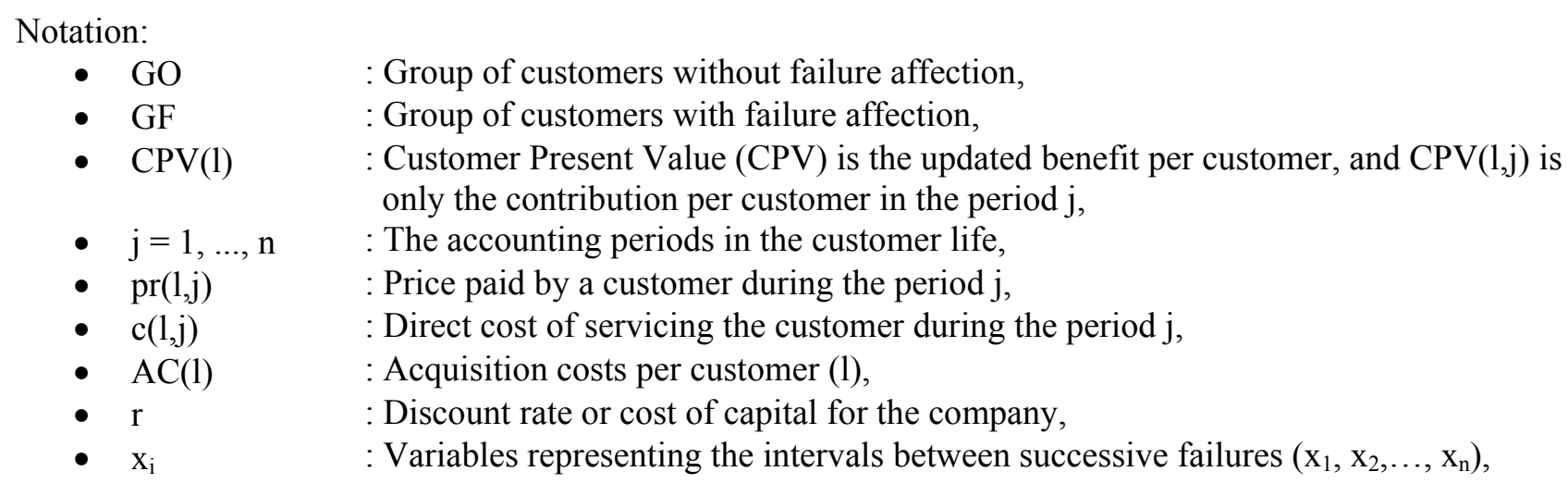




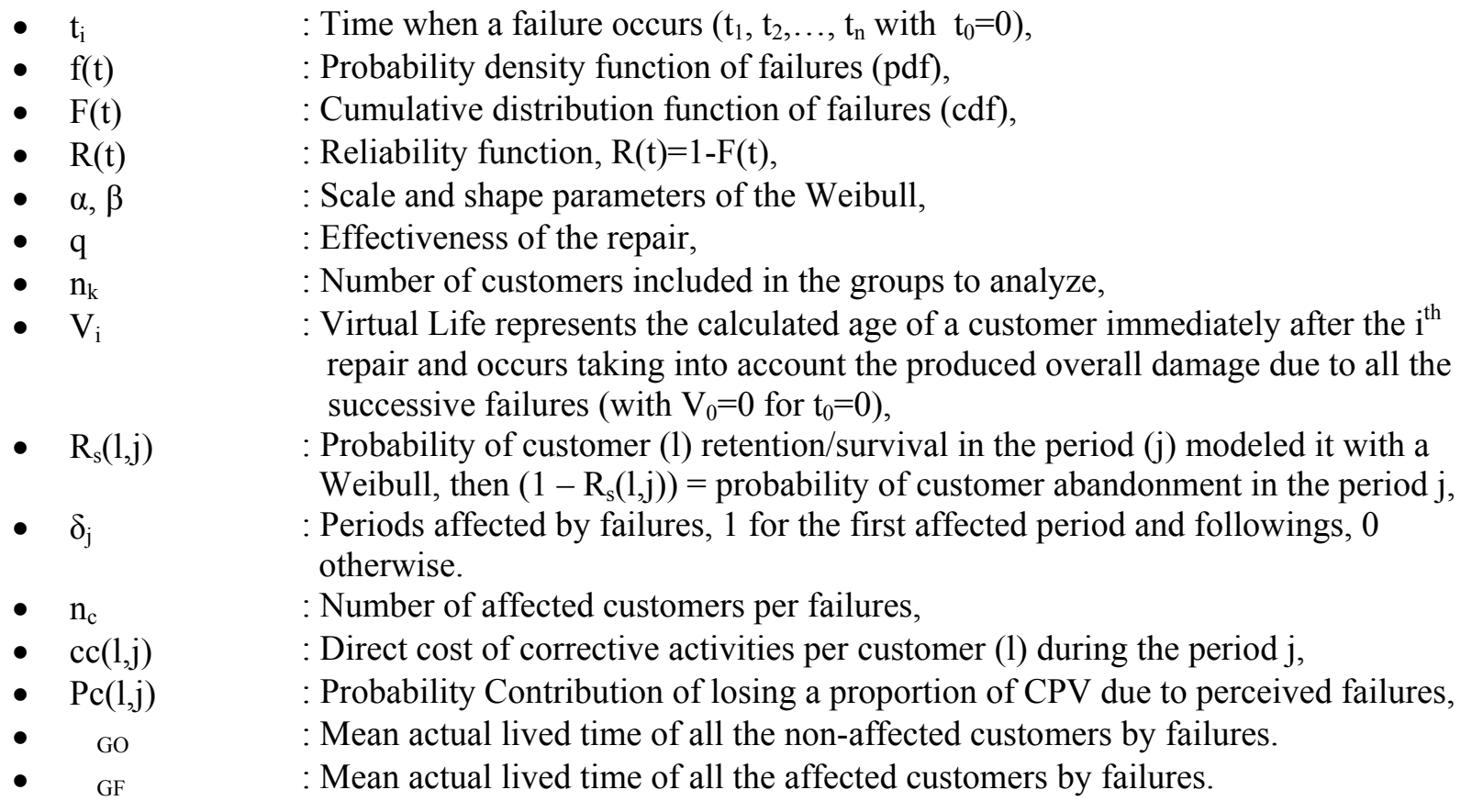

\section{QUALITY, CUSTOMER AFFECTION AND THEIR RELATION TO MAINTENANCE}

Assuming that the evaluation of maintenance's contribution to business is often based solely on the occurrence of critical incidents, it will only be visible to general managers when properly converting preventive and corrective maintenance actions into terms of costs [19]. This refers not only to the maintenance budget, but mainly to relative non-quality costs ("...the knowledge of quality costs helps managers to justify the investment in quality improvement and to assists them in monitoring the effectiveness of the efforts made" [20]). This is the main objective of the methodology developed in this paper and in order to do this it will be supported by quality costs theory. Most literature related to quality associations recommends classifying quality costs in under Prevention, Appraisal and Failure [21, 22] (the PAF scheme):

- Prevention costs are those associated with actions to ensure the desired quality of products/services;

- Appraisal costs are those incurred due to tracking and controlling quality;

- Failure costs are produced to correct failure or damages in products/services. They can be generated internally or externally. These quality costs are known as "non-quality" costs. External non-quality costs are difficult to measure, directly generate customer dissatisfaction, and are probably the most relevant costs to the business.

Inside the PAF scheme applied to this maintenance evaluation, prevention and appraisal costs are considered tangible and directly quantifiable from one year to the next. However, failure costs cannot be considered from a deterministic point of view, due to the uncertainty of occurrences and their consequences. Therefore, it must be handled as a critical incident in the relationship with the customer from a probabilistic approach $[26,27]$. In addition, indicators to support maintenance decisions, for example to invest in preventive or appraisal activities instead of wait for failures (because $\mathrm{P}$ and $\mathrm{A}$ costs are inversely proportional to $\mathrm{F}$ costs), our failure analysis does not only have to focus on a financial year, but also it has to search the total impact during the equipment life-cycle or customer relationships.

During the customer relationship, failures impact service quality in the following ways [25]:

- Failures decrease customer satisfaction. Each failure may modify customer perception of service quality, transmitting bad propaganda into the market (up to 10 partners). According to Keaveney [24], service failures generate $44 \%$ of customer losses, and as a consequence, important changes in "customer life-cycle value". 
- Recurrent failures decrease customer satisfaction even more. Recurrent service affections (against those established in a contract, or determined by the market standards) accelerates negative perception in the customer. According to Svantesson, the evolution of quality should be measured by comparing it with other companies in the sector, competitors, standards and regulations. Some $80 \%$ of customer satisfaction is due to delivering services correctly, and the remaining $20 \%$ is due to resolving claims or problems.

Besides these previous considerations, customer behavior can fluctuate; the customer may remain with the service waiting a monetary refund, or may pursue legal action. In both situations, the customer could do negative propaganda or could keep the bad experience in mind, diffusing it or reminding to the company by mere convenience. Therefore, quantifying this potential behavior according to the failure impact on the service should be beneficial.

In services companies, the most important source of income comes from end-customer invoicing, and these customers are the major justification for business sustainability. Then, understanding of customer value, in the entire commercial relationship with the company is important and an extremely relevant research topic represented by the Customer Present Value (CPV). CPV can be formalized including total income from a customer during a period of time minus all the costs required to serve that customer [29], which is updated depending on the lived time of each customer affected by failures. CPV can be used as a reference benchmark, not only to support the estimation of future profits, but also to improve the customer segmentation process. According to Gupta and Lehmann [29] the equation for CPV could be expressed as follows:

$$
\operatorname{CPV}(1)=\sum_{j=1}^{\mathrm{n}}\left[\frac{[\operatorname{pr}(1, \mathrm{j})-\mathrm{c}(1, \mathrm{j})] \cdot\left[\mathrm{R}_{s}(1, \mathrm{j})\right]}{(1+\mathrm{r})^{\mathrm{j}}}\right]-A C(l)
$$

Consequently, CPV is the present value benefit per customer; it is the total income from a client obtained during its relationship with the company, less direct costs of sale, acquisition, customer loyalty and advertising, discounted according to the interest rate of reference at the time of the study, and considering the probability of retention in each period of the customer life. CPV can be increased if the pricing $\operatorname{pr}(1, \mathrm{j})$ is increased, the servicing costs are decreased $c(1, j)$, or the probability of retention or survival $R_{s}(1, j)$ is improved. The good disposition and work of the maintenance department, the company income can be increased by reducing costs of operation, increasing customer satisfaction and reducing customer loss due to bad services [13, 14 and 15]. In addition, if the quality of the service is well accepted in the market, then company reputation will increase, so new customer acquisition will be facilitated. Based on this, we may evaluate the efficiency of maintenance investments through the violation of existing SLAs as well as historical CPVs.

Accordingly, depending on failures as critical incidents, the customer behavior about the service quality could be represented by a probabilistic approach of the retention, and so based on failure analysis methodologies $[32,33,34]$. In order to quantify the failures consequences, this paper deals with how failures (and the actions to adopt in order to detect, avoid and fix the faults $[15,17]$ ) impact perceived service quality and associated risk of customer abandonment. This calculation is made through a stochastic calculation of the service level. Thus, probability of retention or survival is derived from parametric estimations of the related SLA variables [28, 47], such as MTBF and MTTR (which are characterized with probability distribution functions), accomplishing a "Survival data Analysis". This statistical method demonstrates how a group of individuals will react to a failure after a certain length of time [35, 36, 37].

When analyzing failure recurrence with the purpose of making accurate decisions oriented to business results, measurement of customer retention probability $\left(\mathrm{R}_{\mathrm{s}}\right)$ becomes of vital importance in term of costs, and this can be more important than the repair costs (see Equation 1). A very interesting opportunity appears when we link this type of analysis to historical business data, per different areas of a company, or against competence and regulatory principles in the sector. 


\section{DEVELOPMENT OF THE METHODOLOGY}

The study of retention probability and its relationship with the recurrence of failures, considered as a "Survival data Analysis", focuses on surviving customers facing multiple failures. Understood this term as referring to customers who remain in the company even after experiencing one or more faults. There are different techniques to solve this type of analysis [38, 39, 40, 41, 42, 43]. The intention of our paper is to develop a methodology considering how the recurrence of failures and the probability of survival are correlated with the customer abandonment.

The Generalized Renewal Process (GRP) is proposed to be applied given its ability to describe the rate about the occurrence of events in a repairable system over time. This method is the most flexible technique for modelling the behaviour of a specific system before failures and the quality of repairs considering all possible states on the system age [44] (see equation 2). GRP method is particularly useful applied to the Weibull distribution function, because it returns the values of $\alpha$ and $\beta$ : as well as an indicator of repair quality (q). The repair could compensate a proportion of the damage produced during the time between failures $i$ and $i-1$, but also damages produced in previous intervals. Properly performed failures may improve perception, while poorly solved failures could aggravate it (always speaking in terms of reliability). Therefore, based on the GRP model there are five possible states of the repair efficiency (q).

- $\mathrm{q}<0$, the customer relationship (CR) is rejuvenated better than in the case of a new customer.

- $\mathrm{q}=0$, the $\mathrm{CR}$ is improved to the case of a new customer.

- $0<\mathrm{q}<1$, the $\mathrm{CR}$ is rejuvenated better than old but worse than new.

- $\mathrm{q}=1$, the $\mathrm{CR}$ is maintained equal to old.

- $\mathrm{q}>1$, the $\mathrm{CR}$ is deteriorated worse than old.

There are different formalizations of the GRP process to model equipment evolution over time. The approach is built on the GRP II by Kijima \& Sumita [48], to cover complex systems with multiple equipment and repairs, reducing historical data points and processing power required for the analysis. In this case, simplification of the implementation of the GRP method is based on the study by Mettas and Zhao [45] on Weibull probability distribution function. This function is one of the most broadly used in reliability studies allowing representation of different functions such as exponential, Rayleigh or normal), and evaluated with the Maximum likelihood Estimation (MLE) [46, 47]. In short, the methodology employs GRP with recurrent failures, modelling the probability of customer survival with Weibull functions that let us estimate the impact of each single failure on customer age and maintenance performance, avoiding the failures as a measurement of service quality.

For this purpose, the following starting points have been defined:

- The relationship between the probability of customer abandonment is analyzed considering the survival and abandonment times in two customers groups with similar characteristics, one based on customers with recurrence of failures (GF) searching the impact of failures as critical incident, and other collecting the customers without failure affection (GO).

- For each group, the time series in which the customer requests abandonment (real time) is computed using right censored data (with starting customer age equals to 0 ), see Figure 1.

- All failures are detected and, the preventive and corrective times are negligible compared to the times between failures. The repair could compensate the produced failure impact during the time between failures i and i-1, but also impacts produced in previous intervals. Consequently, depending on the recurrence of failures, the repair efficiency (q) symbolizes the compensation of the damage in customer perception during the time between failures $i$ and $i-1$, but also previous damages.

- To show repair efficiency, a variable denominated Virtual Life $\left(\mathrm{V}_{\mathrm{i}}\right)$ is introduced, whose concept represents the calculated age of a customer immediately after the $i^{\text {th }}$ repair occurs and taking into account the produced overall damage due to all the successive failures (with $\mathrm{V}_{0}=0$ for $\mathrm{t}_{0}=0$ ). Well performed repairs of failures may extend the time between failures and hence the customer relationship with the company reducing its virtual age rejuvenating the customer perception (as in a new captured customer where there is a minor probability of customer abandonment). Meanwhile 
bad performed repairs could reduce the time between failures and so making the customer relationship virtually older (with a higher probability of abandonment). Thus, we could employ the virtual life in comparison to the real age of the customer as a measurement of the maintenance contribution to avoid the recurrence of failures over one customer (until the last failure $\mathrm{x}_{\mathrm{i}}$ ).

$$
V i=q \cdot \sum_{j=1}^{i} q^{i-j} x_{j}=q \cdot\left(x_{i}+v_{i-1}\right)
$$

\section{Figure 1. Customer Survival depending on time}

The mathematical format of the model using Weibull function requires the definition of the failure density function $\mathrm{f}(\mathrm{t})$ and the failure distribution function $\mathrm{F}(\mathrm{t})$ to be expressed in a conditional probability function as follows:

$$
\begin{aligned}
& F\left(\left.x_{i}\right|_{i-1}\right)=\frac{F\left(x_{i}+v_{i-1}\right)-F\left(v_{i-1}\right)}{1-F\left(v_{i-1}\right)}=1-e^{-\left[\frac{\left(x_{i}+v_{i-1}\right)^{\beta}-v_{i-1} \beta}{\alpha}\right]} \\
& f\left(\left.x_{i}\right|_{i-1}\right)=\frac{\beta}{\alpha}\left(\frac{x_{i}+v_{i-1}}{\alpha}\right)^{\beta-1} \cdot \exp \left[-\left[\frac{\left(x_{i}+v_{i-1}\right)^{\beta}-v_{i-1}^{\beta}}{\alpha^{\beta}}\right]\right]
\end{aligned}
$$

We estimate the $\mathrm{f}(\mathrm{t})$, fitting on three parameters $\alpha, \beta$ and $\mathrm{q}$ based on the failure data $\left(\mathrm{N}\right.$ observations $\mathrm{t}_{1}, \mathrm{t}_{2}, \ldots$ $t_{n}$ ) for a time truncated estimation (up to time T), using the Maximum Likelihood Estimation (MLE) method, searching the maximum point in three dimensions for the product of conditional $\mathrm{f}(\mathrm{t})$ :

$$
L\{\text { data } \mid \alpha, \beta, q\}=L\left\{x_{1}, x_{2}, . ., x_{n} \mid \alpha, \beta, q\right\}=\prod_{i=1}^{n} f\left(x_{i} \mid \alpha, \beta, q\right)=L
$$

Continuing with the MLE resolution, according to all the observations for $n_{k}$ customers of similar characteristics, we take logarithms (see Equation 6) and equal to 0 partial derivatives with respect to $\alpha, \beta$ and $\mathrm{q}$ in order to obtain the best fit on these three parameters. To solve with fast convergence Newton method is recommended and the goodness of results can also be analyzed according to Fisher matrix.

$$
\begin{aligned}
& \Lambda=\log L\{\operatorname{datd} \alpha, \beta, q\}=\sum_{k=1}^{n_{k}} n_{k} \cdot(-\ln \alpha+\ln \beta)-\sum_{k=1}^{n_{k}}\left[\left(\frac{T_{k}-t_{k, n_{k}}+v_{n_{k}}}{\alpha}\right)^{\beta}-\left(\frac{v_{n_{k}}}{\alpha}\right)^{\beta}\right]- \\
& -\sum_{k=1}^{n_{k}} \sum_{i=1}^{n}\left[\frac{\left(x_{k, i}+v_{k, i-1}\right)^{\beta}-v_{k, i-1} \beta}{\alpha^{\beta}}\right]+(\beta-1) \cdot \sum_{l=1}^{n} \sum_{i=1}^{n} \ln \left(\frac{x_{k, i}+v_{k, i-1}}{\alpha}\right)
\end{aligned}
$$

The following steps comprise the methodology:

1. Firstly, $\alpha, \beta$ and q parameters have to be calculated in the two customer groups (GO and GF) considering the survival and abandonment times.

2. As a result, the behavior of the two customer groups can be patterned parametrically by the $R(t)=1$ $F(t)$ that could be estimated for each group and discretizing for each period, $R_{s}(1, j)$.

3. Now, the failure impact can be customized as the difference of behavior in the group with recurrent failures against the group without failures. This is represented by the difference of $R_{s}$ among both groups depending on time, where there must be a probability increment ( $\mathrm{Pc}$, Probability 
Contribution) of losing customers due to perceived failures. Hence, there is a better probability of retention in the group of customers without failure affection.

$$
P c(l, j)=\Delta \mathrm{R}_{\mathrm{s}}(1, \mathrm{j})=\mathrm{R}_{\mathrm{s}}^{\mathrm{GO}}(1, \mathrm{j})-\mathrm{R}_{\mathrm{s}}^{\mathrm{GF}}(1, \mathrm{j})
$$

4. Economic loss due to recurrent failures can be determined by the reduction of the above mentioned Customer Present Value (CPV) as a risk, reflecting in the lost monthly payments as a reduction in the probability of survival over an ideal customer relationship without failures. Thus, in order to assess the maintenance contribution in terms of cost, a residual CPV could be deduced due to failures because the expected customer life has been reduced by the occurrence of failures. Consequently, the total Risk is calculated multiplying for all the affected customer per failures $\left(\mathrm{n}_{\mathrm{c}}\right)$, the Probability Contribution $\operatorname{Pc}(1, j)$ by the respective proportion of the CPV for the residual life in periods $(n)$ since the first failure occurrence $\left(\delta_{\mathrm{j}}=0\right.$ in each $\mathrm{j}$ period except in the period where the first failure occurs and the followings periods in which is equal to 1$)$.

$$
\text { Risk }=\sum_{l=1}^{n_{c}} \sum_{j=1}^{n}\left[\frac{[\operatorname{pr}(1, j)-c(1, j)] \cdot\left[\delta_{j} \cdot \operatorname{Pc}(1, j)\right]}{(1+r)^{j}}\right]
$$

5. Finally, the Total Failure Costs (F), from a quality point of view, is calculated counting the cost of all the produced/estimated corrective actions $\left(\mathrm{C}_{\mathrm{F}}\right)$ and plus the total Risk of losing customers for all the affected customers per any failures (see Formula 9, where $\operatorname{cc}(1, \mathrm{j})$ is the mean corrective costs per affected customer and period).

$$
\mathrm{F}=\mathrm{C}_{\mathrm{F}}+\operatorname{Risk}=\sum_{l=1}^{\mathrm{n}_{\mathrm{c}}} \sum_{j=1}^{\mathrm{n}} \frac{\mathrm{cc}(1, \mathrm{j})}{(1+\mathrm{r})^{\mathrm{j}}}+\sum_{l=1}^{\mathrm{n}_{\mathrm{c}}} \sum_{j=1}^{\mathrm{n}}\left[\frac{[\operatorname{pr}(1, \mathrm{j})-\mathrm{c}(1, \mathrm{j})] \cdot\left[\delta_{\mathrm{j}} \cdot \operatorname{Pc}(1, \mathrm{j})\right]}{(1+\mathrm{r})^{\mathrm{j}}}\right]
$$

The calculated Total Failure Cost (directly linked to maintenance performance) can be used to compare alternatives or scenarios, for example against preventive/predictive maintenance actions in order to avoid failures or evaluation activities. Thus, network utilities companies can evaluate, globally or per area, the capital invested and its effect on the customer satisfaction, in order to analyze the use of financial resources in maintenance activities, predicting the financial behavior if there are changes in the reliability of services.

The proposed methodology could be more precise developing the survival reliability per each number of failures (f) inside the group of affecting customers in each period $\left[R_{s 1}(1, j), R_{s 2}(1, j), . ., R_{s f}(1, j)\right]$. Although to simplify the implementation and computation in executive reports, instead of evaluating on real time the risks per each individual affected customer per period (discretized yearly or semiyearly) and area of the network, we can also employ mean values evaluated globally as an approximation. Thus, in terms of the reliability function, the mean $\mathrm{C} \mathrm{V}$ per non-affected customer compared to the reduction of the mean lived time for all the affected customers could be employed as well as the mean corrective cost for all the failures and periods ( $\dot{c} c)$ per affected customer (see Formula 10). That is to say, we could use for all the customers the average mean of the differences among the $\left[R_{s}{ }^{G O}(1, j)\right]$ and $\left[R_{s}{ }^{G F}(1, j)\right]$ for all the periods (i.e. for each semester).

$$
\mathrm{F}=\mathrm{C}_{\mathrm{F}}+\mathrm{Risk}=n_{c} \cdot \dot{\mathrm{c}} \mathrm{c}+n_{c} \cdot \mathrm{CPV} \cdot \operatorname{mean}_{\forall \mathrm{j}}\left\{\left[\mathrm{R}_{\mathrm{s}}^{\mathrm{GO}}(\mathrm{j})-\mathrm{R}_{\mathrm{s}}^{\mathrm{GF}}(\mathrm{j})\right]\right\}
$$

This methodology assesses the impact of reliability on customer satisfaction and retention, streamlining prioritization and decision-making. In order to show the conservation degree of the customer relationship, it can be utilized the survival reliability, the estimated mean virtual life of customers (rejuvenated o degraded from real life) or the repair efficiency $\mathrm{q}_{\mathrm{GRP}}$ (to eliminate failures). Therefore, these variables can be useful to obtain a reasonable comparison among:

- Geographical areas,

- Technical groups,

- Procedures, 
- Changes in operations or organization,

- Equipment and technologies from different vendors,

- Environmental conditions and operations,

- With competitors.

- Etc.

The same methodology could be utilized to segment the group of affected customers depending on the number of suffered failures in order to obtain different survival reliability functions, distinguishing the contribution of each additional suffered failure per customer.

\section{CASE STUDY IN A TELECOMMUNICATION COMPANY}

We will apply the methodology to a telecommunications company to show the implementation of the survival method after repeated failures, compared with the abandonment after no-failures occurrence.

We present a case study based on two customer groups, GO and GF:

- Group GO refers to customers that abandoned the telecommunications services (canceling the contract) after a certain time period. They never experienced a failure incident.

- Group GF is about customers that experienced several recurrent failures. After a determined number of failures, they abandoned the telecommunications services.

Each sample group corresponds to 200 customers, and considering the lost and maintained customers in their related time, we would deduce from the Weibull estimation the survival probability and other parameters. To do this, our methodology is developed based on the 3-parameter Weibull GRP method to obtain the probability of abandonment per customer. The solution is calculated by solving the Maximum Likelihood Estimation (MLE) through the Newton-Raphson statistical method to converge quickly. The smoothing of the solution is evaluated through the previously mentioned Fisher Matrix.

\subsection{Group GO - Customers leaving the company after no failures}

Figure 2 presents the data sample for group GO. The histogram shows the dispersion of the data for the abandonment time of 200 customers. From the histogram, it can be noticed that the majority of the abandonments occur between time 600 and 900 days. The arithmetic mean is 717.37 and the standard deviation is 292.12 . The probability density function also is characterized in the histogram as a solid line.

\section{Figure 2. Histogram of customers leaving the company. Data for case GO}

The Weibull parameters are $\beta=2.564$ and $\alpha=800.64$. Other important values such as reliability (R), unreliability (Q), MTTF and failure rate of the analyzed sample, are shown in Table 2. All the factors have been calculated when $t=100$. MTTF and Failure Rate both represent in this case mean life for customer abandonment and abandonment rate.

Table 2. Reliability values for Case GO

\begin{tabular}{|c|c|}
\hline Index & Value \\
\hline $\mathrm{R}(\mathrm{t}=100)=$ & 0.995183 \\
\hline $\mathrm{Q}(\mathrm{t}=100)=$ & 0.004817 \\
\hline $\mathrm{MTTF}=$ & 710.84 \\
\hline Failure rate $=$ & 0.000124 \\
\hline
\end{tabular}

\subsection{Group GF-Customers leaving the company after recurrent failures}

In this case, the group is composed of 200 customers from the telecommunications company who suffered one or more failures before abandoning the services. Figure 3 presents a histogram of the abandonment times. From the histogram, it can be noticed that the majority of the abandonments occur around 534 days. 
The arithmetic mean is 566.36 and the standard deviation is 315.60 . According to the number of failures, all 200 customers experienced at least one failure, 77 customers experienced two failures, and 10 customers experienced three failures before the abandonment. Figure 4 shows the distribution of the number of failures experienced by customers, sorted according to the occurrence time. Each line color represents a first, second or third failure and the abandonment moment.

\section{Figure 3. Histogram of abandonment times for case study GF.}

\section{Figure 4. Recurrent failures per customer vs. Time for case study GF.}

The GRP parameters for case GF (a parametric recurrent event analysis) are $\beta=1.3067$ and $\alpha=442.09$. The repair effectiveness (q) between failures is 0.75766 which indicates a rejuvenation of the customer relationship in each successive failure, the appearance of $2^{\text {nd }}$ and $3^{\text {rd }}$ failures are less frequent than the $1^{\text {st }}$ failure. That is, according as the recurrence of failure increases, the frequency of appearance of new failures decreases. Consequently, the virtual life could be representative indicator of the maintenance impact on perceived quality, developing comparisons among geographical areas within the same company (see example in Figure 5), and guiding loyalty campaigns in order to reinforce company reputation in areas with $\mathrm{q}$ next to or greater than 1 .

\section{Figure 5. Internal benchmarking of repair efficiency among areas.}

Other important values as reliability (R), unreliability (Q), instantaneous MTBF and instantaneous failure intensity are shown in Table 3. The consistency of the obtained Weibull GRP according to the considered number of customers (n), as sensibility analysis, is included in Table 4.

Table 3. Reliability values for case GF

\begin{tabular}{|c|c|}
\hline Index & Value \\
\hline $\mathrm{R}(\mathrm{t}=100)=$ & 0,866432 \\
\hline $\mathrm{Q}(\mathrm{t}=100)=$ & 0.133568 \\
\hline $\mathrm{MTBF}=$ & 407.88 \\
\hline Inst. Failure Intensity $(\mathrm{t}=100)=$ & 0.001854 \\
\hline
\end{tabular}

Table 4. Analysis according to the considered number of customers (n).

\begin{tabular}{|c|c|c|c|c|}
\cline { 2 - 5 } \multicolumn{1}{c|}{} & $\mathrm{n}=50$ & $\mathrm{n}=100$ & $\mathrm{n}=150$ & $\mathrm{n}=200$ \\
\hline$\beta$ & 1,05 & 1,15 & 1,24 & 1,31 \\
\hline$\alpha$ & 489,49 & 457,36 & 444,01 & 442,09 \\
\hline $\operatorname{Var}(\beta)$ & $1,10 \mathrm{E}-02$ & $6,44 \mathrm{E}-03$ & $4,95 \mathrm{E}-03$ & $4,15 \mathrm{E}-03$ \\
\hline $\operatorname{Cov}(\alpha, \beta)$ & $1,09 \mathrm{E}-04$ & $3,70 \mathrm{E}-06$ & $1,70 \mathrm{E}-06$ & $9,00 \mathrm{E}-06$ \\
\hline $\operatorname{Var}(\alpha)$ & 0,000001 & $2,1232 \mathrm{E}-07$ & $5,89286 \mathrm{E}-08$ & $2,17728 \mathrm{E}-08$ \\
\hline LK Value & $-495,45$ & $-1027,08$ & $-1539,92$ & -1990 \\
\hline
\end{tabular}

\subsection{Comparative analysis Case GO vs. Case GF}

To analyze the differences between the no-failures recurrence case study (solid lines), and the recurrent failure case study (dashed lines), several graphics have been generated to compare the main reliability indicators.

- Figure 6 shows unreliability behavior for both cases. From this image, it can be observed that the cumulated probability of customer abandonment has a faster growth in case GF (recurrent failures) than in case GO (without failures). 
- Figure 7 presents the instantaneous failure probability for both cases. This Figure shows that the abandonment probability is higher for case GF, and above all is higher at the beginning of the customer relationship when recurrent failures occur.

- Figure 8 compares the reliability for both cases. The downfall in reliability for case GF is faster than for case GO.

- Finally, Figure 9 shows the comparison of cumulative failure rates for both cases.

These graphs are crucial to understand and characterize the behavior of customers depending on the perceived quality related to service reliability. In addition, this analysis can allow companies to forecast the effect of reliability changes. Consequently this is decisive information for decision-making in maintenance.

Figure 6. Comparison unreliability vs. time Figure 7. Comparison instantaneous failure probability

Figure 8. Comparison reliability vs. time

Figure 9. Comparison cumulative failure rate

\subsection{Results and discussion}

The first important data obtained from the previous analysis are the mean times when abandonments occur. For case GO, the MTTF is 710.84 days. This indicates that in cases without failures, the customer decides to abandon the service at time 710.84. The arithmetic mean time of abandonment is 717.37 . For case GF, the instantaneous MTBF is 407.88 and the arithmetic mean time of abandonment is 566.36. This comparison indicates that customer abandonments occur earlier in case GF, when recurrent failures are experienced. In consequence this reduction in the customer relationship impacts directly on the quantity of end-customer invoicing, producing company financial losses via the reduction in CPV. Other reliability parameters shown in Table 5, also indicate the negative impact in the customer relationship due to failures in group GF compared to the group GO. In this table, the reliability factor has been calculated for each semester period of the CPV, where $i$ the difference is remarkable between the $\left[R_{s}{ }^{G O}(j)\right]$ and $\left[R_{s}{ }^{G F}(j)\right]$, which is not constant, but rather changes from one period to other following the behaviour of the two reliability Weibull functions (although the average mean of the differences for all the periods is $32 \%$.

Table 5. Comparison of some reliability parameters. Case GO vs. case GF.

\begin{tabular}{|c|c|c|c|}
\hline & $\begin{array}{c}\text { Case study GO } \\
\text { (no failures) }\end{array}$ & $\begin{array}{c}\text { Case study GF } \\
\text { (recurrent failures) }\end{array}$ & $\begin{array}{c}\text { Difference } \\
(\%)\end{array}$ \\
\hline $\begin{array}{c}\text { Arithmetic mean for } \\
\text { abandonment }=\end{array}$ & 717.37 & 566.36 & $21 \%$ \\
\hline $\mathrm{MTTF} / \mathrm{MTBF}=$ & 710.843705 & 407.88 & $43 \%$ \\
\hline $\mathrm{R}(\mathrm{j}=1, \mathrm{t}=180)=$ & 0.978444464 & 0.734133324 & $24 \%$ \\
\hline $\mathrm{R}(\mathrm{j}=2, \mathrm{t}=360)=$ & 0.879116396 & 0.465523471 & $41 \%$ \\
\hline $\mathrm{R}(\mathrm{j}=3, \mathrm{t}=540)=$ & 0.694661556 & 0.272858239 & $42 \%$ \\
\hline $\mathrm{R}(\mathrm{j}=4, \mathrm{t}=720)=$ & 0.466854332 & 0.150842271 & $32 \%$ \\
\hline $\mathrm{R}(\mathrm{j}=5, \mathrm{t}=900)=$ & 0.259301801 & 0.079505553 & $18 \%$ \\
\hline
\end{tabular}

Therefore, if the number of failures or the affected customers by them is high, the impact of maintenance performance in terms of costs is significant. 


\subsection{Risk Comparison of Losing Customers in different areas of GF Group}

Finally, this analysis can be particularized in the company Customer Relationship System (CRM) for any customer directly using real-time calculations or simplifying through approximations using mean values. Thus, this methodology calculates the risk of losing customers and the total failure costs (F), and distinguishes areas characterized by different survival reliability $\left[\mathrm{R}_{\mathrm{S}}^{\mathrm{GF}}(\mathrm{t})\right]$ and repair effectiveness $\left(\mathrm{q}_{\mathrm{GRP}}\right)$. For this example, two groups of customers with affection of recurrent failures are compared from different areas, employing the simplified implementation through mean values of mean corrective cost $\dot{c} \mathrm{c}$, mean $\mathrm{C} \mathrm{V}$, and the mean difference among the survival reliabilities.

Supposing that Evaluation and Prevention costs are the same in both GF areas, 0.45 M€ and 1.15 M€ respectively, then the comparison among areas must be determined by failure costs as sum of corrective and risk costs. To simplify, for the both areas we will employ as $\left[\mathrm{R}_{\mathrm{s}}^{\mathrm{GO}}(\mathrm{t})\right]$ the Weibull determined in Group GO previously. Therefore, if one area (Area1), has arithmetic mean $=566.36$, standard deviation $=315.6,\left[\mathrm{R}_{\mathrm{s}}^{\mathrm{GF} 1}\right.$ (t)] (obtained in point 4.2 by Weibull GRP analysis) with parameters $\beta_{1}=1.3067, \alpha_{1}=442.09$ and $\mathrm{q}_{1}=0.75766$. Another area (Area2) has arithmetic mean $=509.77$, standard deviation $=214.47,\left[\mathrm{R}_{\mathrm{s}}{ }^{\text {GF2 }}(\mathrm{t})\right]$ (deduced in the same way by Weibull GRP analysis) with parameters $\beta_{2}=1.52966, \alpha_{2}=412.24$ and $\mathrm{q}_{2}=0.67318$. Consequently, both areas are compared through Failure Costs, where the average mean of the difference among the [RsGO (j)] and [RsGF (j)] for all the periods is $32 \%$ in the Area1 and $35 \%$ in the Area2 (see Table 6).

Table 6. Risk analysis comparison between the two areas

\begin{tabular}{|c|c|c|}
\hline & Area1 & Area2 \\
\hline Total Appraisal Costs & $0.45 \mathrm{M€}$ & $0.45 \mathrm{M€}$ \\
\hline Total Prevention Costs & $1.150 \mathrm{M€}$ & $1.150 \mathrm{M€}$ \\
\hline Mean Corrective Costs ( $\dot{c} \mathrm{c})$ & $105 €$ & $105 €$ \\
\hline $\mathrm{n}_{\mathrm{c}}$ (mean number affected customers) & 11,240 & 13,570 \\
\hline Total Corrective Costs & $1.180 \mathrm{M} €$ & $1.425 \mathrm{M} €$ \\
\hline \multirow{2}{*}{$\begin{array}{r}\text { mean }\left\{\left[\mathrm{R}_{\mathrm{GO}}-\mathrm{R}_{\mathrm{GF}}\right]\right\} \\
\mathrm{CPV}\end{array}$} & $32 \%$ & $35 \%$ \\
\hline & $1,415 €$ & $1,415 €$ \\
\hline Risk (€) & $\begin{array}{l}11,240 \cdot 1,415 \cdot 0.32= \\
5.089 \mathrm{M} €\end{array}$ & $\begin{array}{l}\text { 13,570·1,415·0,35 } \\
=6.720 \mathrm{M} €\end{array}$ \\
\hline TOTAL F COST (€) & $6.270 \mathrm{M} €$ & $8.145 \mathrm{M} €$ \\
\hline
\end{tabular}

Table 6 shows failure costs can be different depending on the maintenance performance among areas. The number of failures and the produced risks due to customer abandonments by failures contribute to the difference of failure costs. The risk can be critical when failures have a high impact customer abandonments, mainly due to a decrease in retention probability, and consequently reducing the customer lived time. Thus, in the case of Area 1 the risks are 5.089 M€, much higher than prevention or corrective costs, however in Area 2 the risks are $6.632 \mathrm{M} €$ because the number of failures and probability of abandonment are both higher.

As a result, the impact in terms of costs on perceived quality is determined mainly due to the difference in Risk costs (see Figure 10) for each area. Maintenance contribution can be analyzed by balancing A+P costs versus $\mathrm{F}$ costs, considering direct costs as corrective actions and indirect costs as perceived quality, and even so utilizing these evaluations characterized per any failure mode deciding to act with prevention instead of correction activities. Consequently, the maintenance contribution of both areas to the perceived quality and customer retention is unequal mainly due to the failure costs (area2>area1), directly proportional to the number of failures and indirectly to the potential loss of customers. In addition, the repair efficiency also shows maintenance performance in the area in order to avoid recurrent failures $\left(\mathrm{q}_{2}=0.67318<\mathrm{q}_{1}=0.75766\right)$. This example indicates the possibility of providing more material resources to preventive/predictive maintenance in order to reduce losses. 


\section{Figure 10. Costs comparison for case Area1 and case Area2}

Additionally, our methodology classifies groups of affected customers by failures in several subgroups with the same number of suffered failures. For example, one subgroup with customers with only one failure, other with two, and so on. In this way, by applying the same formulae we specify recurrent increments of $\left[\mathrm{R}_{\mathrm{s}}^{\mathrm{GF}}\right.$ $(1, j)$ ] for each supplemental suffered failure. In our example the increment of the abandonment probability from customers with 1 failures against 0 is x1.133, with 2 failures instead of one is the $x 1.38$ and from 3 failures instead of two is x1.43 as average means of the difference among the [RsGO (j)] and [RsGF (j)] for all the periods (see Table 7 and Figure 11).

Table 7. Probability increment of customer abandonment according to number of recurrent failures

\begin{tabular}{|c|c|c|c|c|}
\cline { 2 - 5 } \multicolumn{1}{c|}{} & $\alpha$ & $\beta$ & MTBF & $\begin{array}{c}\text { \% Inc. } \\
\text { Probability }\end{array}$ \\
\hline GO & 800,64 & 2,56 & 710,85 & \\
\hline A1x1 & 614,99 & 2,27 & 544,76 & $13,30 \%$ \\
\hline A1x2 & 325,21 & 1,28 & 301,17 & $38,18 \%$ \\
\hline A1x3 & 267,81 & 1,44 & 242,98 & $43,67 \%$ \\
\hline
\end{tabular}

\section{Figure 11. Reliability according to number of recurrent failures}

From our analysis, the following inferences can be deduced:

a) Maintenance contributes to the profits of the company, due to maintenance increases the probability that a customer stays (does not abandon the service).

b) Not only is it important to prevent failures, but also their recurrence. As failures occur more sporadically, the repair effectiveness is improved. This improvement causes a decrease in customer abandonment. Also, according as the recurrence of failures is increased, the potential lost customers increases, especially if the service disruptions are more than those stipulated in the contract.

c) Comparison of these two cases reveals that the investment in preventive/predictive maintenance is widely recommended to achieve good levels of reliability, reducing the implicit risk of customer abandonment and the costs of corrective activities.

d) From an automated Weibull analysis, it is possible to determine the expected reliability of services for a determined time, in order to prevent a possible impact on the customer, and to design marketing and loyalty campaigns appropriate to each customer history. These campaigns can be targeted specifically at geographical areas or environmental/technological conditions with higher risk of recurrent failures, in order to prevent abandonments and company image loss.

e) This kind of analysis can be useful also to compare the performance of different subcontractors or technologies, and to compare improvements within the same process; for example by analyzing the repair effectiveness through the recurrence of failures.

f) Furthermore, the total Failure costs (F) are higher if it is considered that the transmission of bad propaganda up to 10 partners or customers increases the abandonment probability of them and, that the bad propaganda and the failure impact decreases the number of new purchases. 


\section{CONCLUSIONS}

Network utilities are complex companies in which failure occurrence impacts on the quality perceived by customers. Use of ICT systems/tools and quality improvement methodologies for maintenance management are essential to stand in the market and to obtain benefits. Maintenance and quality are closely related areas, especially in what corresponds to customer satisfaction. Loyalty of customers depends on service reliability. When the quality perception becomes worse than the conditions offered in the contract, or infringes on the patience of customer (due the number of failures or their duration), the customer abandons the service, meaning financial losses.

Failures analysis for prediction, prevention, correction and the estimation of their consequences is an issue of vital importance. The methodology proposed in this paper is focused on analyzing the economic implications of maintenance and the occurrence (and reoccurrence) of failures in different scenarios, calculating the economic risk of the failure and comparing it with the costs of prevention.

Maintenance performance affects the offered and the perceived quality by the customers, circumstance that is shown through the proposed methodology in our case studies. Investments in maintenance activities (especially preventive/predictive) represent economic advantages. The cases analyzed in this paper showed that investment in preventive maintenance actions is economically viable, as that its direct effect is reducing customer's abandonment rates, and even diminishing the costs of corrective activities also. On the contrary, when number of failures or affected customers increases, especially if failures are recurrent, the impact on costs is significant. In this way a direct relation is observed among the execution of preventive maintenance activities, reliability of services and customer satisfaction, producing significant financial consequences.

The proposed methodology, with the intention of calculating the abandonment probability based on the lifetime of each customer, can be used also as an automated routine to determine the expected reliability of the services for a determined time, and geographical zone. Furthermore, it can be utilized to prevent a possible negative impact on the customer, as well as to design marketing and loyalty campaigns appropriate to each customer circumstance. The methodology is useful when comparing different technical or management alternatives, or to determine if the investment in preventive/predictive maintenance has been profitable.

Assessment of maintenance in network distribution companies should not be only done in terms of budget, but also in terms of real profits directly observable and those due to the avoided damages. Therefore, our methodology takes into account the impacts of risks, later reduced, allowing maintenance management to be accountable and comparable with other organizations or reference standards, from different areas and levels of detail, identifying improvements in network reliability and ensuring service quality from customer, business and society perspectives.

\section{Acknowledgements}

The authors wish to thank the Institution "Fundación Iberdrola" for providing a research grant during the years 2011 and 2012, making the development of projects possible related to the implementation of advanced maintenance strategies, technologies and services.

This research is funded by the Spanish Ministry of Science and Innovation, Project EMAINSYS (DPI201122806) "Sistemas Inteligentes de Mantenimiento. Procesos emergentes de E-maintenance para la Sostenibilidad de los Sistemas de Producción, besides FEDER funds."

\section{References}

[1] Küssel R, Liestmann V, Spiess M, Stich V. "Teleservice" a customer oriented and efficient service. Journal of Material Processing Technology 2000; 107: 363-371. 
[2] Murthy DNP, Atrens A, Eccleston JA. Strategic maintenance management. Journal of Quality in Maintenance Engineering 2002; 8(4): 287-305.

[3] Zhu G, Gelders L, Pintelon L. Object/objective-oriented maintenance management. Journal of Quality in Maintenance Engineering 2002; 8(4): 306-318.

[4] Gómez JF, Crespo A. Framework for implementation of maintenance management in distribution network service providers. Reliability Engineering and System Safety 2009; 94(10): 1639-1649.

[5] Newbery DMG (2002) Privatization, restructuring, and regulation of network utilities. MIT Press, Cambridge.

[6] Dixon JR. Design Engineering: Inventiveness, Analysis, and Decision Making. New York: McGraw-Hill, Inc.; 1966.

[7] Van Vliet B, Chappells H, Shove E (2005) Infrastructures of consumption: environmental innovation in the utility industries. Earthscan Publications Limited, London ISBN 1-85383-996-5.

[8] Gellings GW (2009) The retail electricity service business in a competitive environment. In: Bausch Andreas, Schwenker Burkhard (eds) Handbook Utility Management. Springer, Berlin, pp 545-558.

[9] Remy E, Corset F, Despréaux S, Doyen L, Gaudoin O. An example of integrated approach to technical and economic optimization of maintenance. Reliability Engineering and System Safety 2013; 116: 8-19.

[10]Parasuraman A, Zeithaml VA, Berry LL. A conceptual model of service quality and its implications for future research. Journal of Marketing 1985; 49: 41-50.

[11]Johnson RL, Tsiros M, Lancioni RA. Measuring Service Quality: A System Approach. Journal of Services Marketing 1995; 9(5): 6-19.

[12]Bitner M, Booms B, Tetreault M. The service encounter: diagnosing favourable and unfavourable incidents. Journal of Marketing 1990; 54: 71-86.

[13]Zeithaml VA, Bitner MJ. Services Marketing: Integrating Customer Focus Across the Firm. Boston: McGraw-Hill Higher Education; 2003.

[14] Wacker G, Tollefson G. Electric power system customer interruption cost assessment. Reliability Engineering and System Safety 1994; 46(1): 75-81.

[15] Yanamandram V, White L. Switching barriers in business-to-business services: a qualitative study. International Journal of Service Industries Management 2006; 17(2): 158-192.

[16] De Matos CA, Henrique JL, Vargas Rossi CA. Service recovery paradox: a meta-analysis. Journal of Service Research 2007; 10(1): 60-77.

[17] Maxham JG III. Service recovery's influence on consumer satisfaction, positive word-ofmouth, and purchase intentions. Journal of Business Research 2001; 54: 11-24.

[18]Tschohl J. Achieving excellence through customer service. Minnesota: Best Sellers Publishing; 1996.

[19] Crosby PB. Quality is free. New York: Mentor Books; 1979.

[20]Dale BG, Plunkett JJ. Quality Costing. Hampshire: Gower Publishing; 1991.

[21]ASQC. Quality costs: what and how. New York: American Society for Quality Control; 1970.

[22]BS 4778. Quality vocabulary. London: British Standards Institute; 1987.

[23] Peters T. Thriving on Chaos: Handbook for a Management Revolution. New York: Alfred A. Knopf; 1987.

[24]Keaveney S. Customer switching behavior in service industries: an exploratory study. Journal of Marketing 1995; 59:71-82.

[25] Goodman J. Technical assistance research program (TARP). USA: US Office of consumer affairs study on complaint handling in America; 1986.

[26] Avizienis A, Laprie JC, Randell B. Fundamental concepts of dependability. LAAS-CNRS; Research report No. 1145; April 2001.

[27] Gómez Fernández JF, Crespo Márquez A. Maintenance Management in Network Utilities: framework and practical implementation. London: Springer-Verlag; 2012.

[28] Greves D, Schreiber B. Engineering costing techniques in ESA; 1993. Available online: http://esapub.esriu.esa.it.pointtobullet/greves1.html

[29] Gupta S, Lehman DR (2005) Managing customers as investments: the strategic value of customers in the long run. Wharton School Publishing, New Jersey. 
[30] Woodhouse J. Managing industrial risk. London: Chapman Hill; 1993.

[31] Wilson RL. Operations and support cost model for new product concept development. In: Proceedings of the 8th Annual Conference on Components and Industrial Engineering 1986: 128131.

[32]UNE 200001-3-11. Gestión de la confiabilidad. Parte 3-11: Guía de aplicación. Mantenimiento centrado en la fiabilidad. UNE; 2003.

[33]Dekker R. Applications of maintenance optimization models: A review and analysis. Reliability Engineering and System Safety 1996; 51: 229-240.

[34] Wang W. Condition based maintenance modeling. In: Kobbacy KAH, Murthy DNP (eds) Complex Systems maintenance handbook. London: Springer; 2008.

[35] Parmar MKB, Machin D. Survival analysis: a practical approach. Chichester: Wiley; 1996.

[36] Cox DR, Oakes D. Analysis of survival data. London: London Chapman and Hall; 1984.

[37]Klein J, Moeschberguer M. Survival analysis techniques for censored and truncated data. New York: Springer; 1997.

[38] Andersen PK, Borgan O, Gill R, Keilding N. Statistical models based on counting process. New York: Springer; 1993.

[39]Blischke WR, Murthy DNP. Reliability modelling, prediction and optimization. New York: Wiley; 2000.

[40]Hosmer DW, Lemeshow S. Regression modeling of time to event data. New York: Wiley; 1999.

[41] Hougaard P. Analysis of multivariate survival data. New York: Springer; 2000.

[42]Lee ET. Statistical methods for survival data analysis. New York: Wiley; 1992.

[43] Harrell FE. Regression modeling estrategies. New York: Springer; 2001.

[44] Yañez M, Joglar F, Mohammad M. Generalized renewal process for analysis of reparable systems with limited failure experience. Reliability Engineering and System Safety 2002; 77: $167-$ 180.

[45] Mettas A, Zhao W. Modeling and analysis of repairable systems with general repair. Proceedings of the Reliability and Maintainability Symposium 2005: 176-182, ISBN: 0-7803-88240 .

[46]Cohen AC. Maximum likelihood estimation in the Weibull distribution based on complete and on censored samples. Technometrics 1965; 7(4): 579-588.

[47]Harter HL, Moore AH. Point and interval estimators based on order statistics, for the scale parameter of a Weibull population with known shape parameter. Technometrics 1965; 7(3):405422.

[48] Kijima M, Sumita N. A useful generalization of renewal theory: counting process governed by non-negative Markovian increments. Journal of Applied Probability 1986; 23: 71-88. 